\title{
Anti- and Pro-Oxidative Effect of $\alpha$-Eleostearic Acid on the Autoxidation of Linoleic Acid
}

\author{
Badawy, W.Z. \\ Food Technology Dept., Fac. of Agric., Kafrelsheikh University, Egypt.
}

Received: 14 January, 2018

Revised: 28 February, 2018

Accepted: 11 March, 2018

\begin{abstract}
In this study, fatty acid composition of tung oil and the remaining fatty acid contents after oxidation were determined. Moreover, the oxidative stability of $\alpha$-ESA was compared with linoleic acid (LA), linolenic acid (LnA), arat chidonic acid (AA) and ecosapentaenoic acid (EPA) during auto-oxidation in the dark at $40^{\circ} \mathrm{C}$. The results indicated that $\alpha$-ESA content of tung oil was $79.45 \%$. It was observed that the contents of remaining $\alpha$-ESA, LA, LnA, AA and EPA after $24 \mathrm{~h}$. were $0,72.7,53,13$ and $8.2 \%$, respectively. Comparison between conjugated and non-conjugated fatty acids with the same number of double bonds showed that the conjugated fatty acid (CFA) declined more rapidly and fatty acid with more double bonds also degraded faster. The hydroperoxide content at $0.1,0.2,1$ and $5 \%$ of $\alpha$-ESA were $673,762,828$ and $916 \mathrm{mM}$ at 8 days and $40^{\circ} \mathrm{C}$, respectively. Meanwhile, the peroxide content of methyl linoleate without $\alpha$-ESA (control) was $563 \mathrm{mM}$ at 8 days and $40^{\circ} \mathrm{C}$.
\end{abstract}

Key words: Tung oil, a-eleostearic acid, oxidative stability, auto-oxidation.

\section{INTRODUCTION}

Tung oil tree (Vernicia fordii) is a natural woody oil plant in subtropical areas of China. This important economical tree has been cultivated in China for the production of tung oil for centuries. Tung seeds hold $50-60 \%$ oil with about $80 \%$ $\alpha$-eleostearic acid (9 cis, 11 trans and 13 trans octadecatrienoic acid). Tung oil is easily oxidized due to the presence of three conjugated double bonds in its structure (Tan et al., 2011).

As a kind of oil plant, the specific uses of tung oil in industry are attributed to $\alpha$-eleostearic acid, a kind of unsaturated fatty acid found in it. After additional processing of tung oil, the value of tung oil rises sharply and the processed oil has numerous uses in many fields. In recent years, the yield of tung oil has increased quickly with a rise in cultivated areas of tung tree, which resulted in overstock at one time. Tung oil can be used in the chemical and medical manufactured (Ji et al., 2002, Min et al., 2005).

Some plant seed oils are known to contain conjugated fatty acids (CFA) such as $\alpha$-eleostearic acid $(\alpha$-ESA; 9c, 1lt, 13t-18:3), calendic acid (8t, 10t, $12 \mathrm{c}-18: 3 ; \mathrm{n}-6)$ and parinaric acid $(9 \mathrm{c}, 11 \mathrm{t}, 13 \mathrm{t}, 15 \mathrm{c}-$ 18:4). Additionally, CLA (9,11-18:2, conjugated dienoic acid) is well known to be a component of several dairy products including milk and cheese (Ha et al., 1987, Lin et al., 1995). The CLA has been shown to have properties as anti-carcinogenic and anti-obesity agent in animal studies (Park et al., 1999). Furthermore, it was observed that tung oil fatty acids (mainly consisting of eleostearic acids) induce cytotoxic actions against human tumor cells as efficiently as the conjugated trienoic fatty acids (Igarashi \& Miyazawa, 2000).

The conjugated linolenic acid (CLN) is a group of positional and geometric isomers of octadecatrienoic acids that hold three conjugated double bonds. The CLN can be present in tung oil, pomegranate seed oil, catalpa seed oil, balsam pear seed oil and cherry seed oil. Tung oil contains principally two CLN isomers, $\alpha$-ESA (c9, t11, t13-18:3) and $\beta$ - eleostearic acid ( $\mathrm{t} 9, \mathrm{t} 11, \mathrm{t} 13-18: 3)$ (Takagi \& Itabashi, 1981).

Conjugated polyunsaturated fatty acids (PUFA) are exclusive fatty acid that contains conjugated double bonds in their molecules. Among these conjugated FA, CLA are well known, and many research articles have been published on the biological activities of CLA (Pariza et al., 1999, Pariza et al. 2003).

At present, CFAs have attracted substantial attention because of their potentially beneficial bio- 
logical effects attenuating lifestyle-related diseases. The CFAs include a mixture of positional and geometric isomers of PUFA with conjugated double bonds. Theoretically, amounts of CFA isomers are comprise numerous combinations of numerical, positional and geometrical shapes of conjugation in double bonds. The $\alpha$-eleostearic acid is a CFA, which can be extracted from tung (Aleurites fordii) oil (Rainer \& Heiss, 2004).

The mechanism of autoxidation of methyleneinterrupted fatty acid double bonds is fine established and includes a catalytic process which proceeds via a free radical mechanism. The initiation step consists of addition alkyl radical formation $(R \cdot)$ in the carbon adjacent to the double bond and the propagation step results in addition of oxygen to form alkyl peroxyl radicals (ROO·), hence the oxygen consumed is primarily converted to hydroperoxides (ROOH) (Frankel, 2005).

The aim of the present study was conducted to determine fatty acid composition of tung oil. The oxidative stability of methyl $\alpha$-ESA was compared with methyl esters containing linoleic acid (LA), linolenic acid (LnA), arachidonic acid (AA) and ecosapentaenoic acid (EPA) which were auto-oxidized in the dark at $40^{\circ} \mathrm{C}$. To evaluate the oxidative stability, fatty acid composition and the remaining FA content were determined.

\section{MATERIALS AND METHODS}

\section{Materials:}

Stearic acid (18:0), linoleic acid (LA) (18:2n6), linolenic acid (LnA) (18:3n-3), arachidonic acid (AA) (20:4n-4), ecosapentaenoic acid (EPA) (20:5n5) and BHT were obtained from Sigma Chemical Co. (St. Louis, MO). $\alpha$-ESA (79 \% purity) was isolated from tung oil. Tung oil was provided by Nippon Oil and Fats Co. Ltd. (Tokyo, Japan).

\section{Methods:}

\section{Preparation and purification of methyl fatty acids from tung oil.}

Fatty acid methyl esters (FAMEs) were obtained from tung oil (triacylglcerol) by transesterification using sodium methoxide as the catalyst. After placing tung oil (ca. $10 \mathrm{~g}$ ) and toluene (20 $\mathrm{ml}$ ) into a $100 \mathrm{ml}$ screw- capped flask, $70 \mathrm{ml}$ of methanol and $10 \mathrm{ml}$ of $28 \%$ sodium methoxide in methanol were added, and transesterification was completed by heating the mixture with stirring at
$60{ }^{\circ} \mathrm{C}$ for $1 \mathrm{hr}$. The reaction was stopped by the addition of acetic acid $(5 \mathrm{ml})$. The reaction mixture was put into a separatory funnel, added hexane $(200 \mathrm{ml})$ and water $(100 \mathrm{ml})$, and mixed. The lower layer was re-extracted with hexane $(100 \mathrm{ml})$. The hexane layer was combined and washed with water for several times. The hexane solution was dried under vacuum using a rotary evaporator. The recovered FAMEs were refined on a silicic acid column (silica-gel, ca. $50 \mathrm{~g}$ ) by eluting them with hexane $(100 \mathrm{ml})$ and a solution of hexane / ethyl acetate $\mathrm{v} / \mathrm{v}(96: 4,200 \mathrm{ml}$; 94:6, $200 \mathrm{ml})$. The elutions were collected each $50 \mathrm{ml}$ and checked by silica - gel TLC developed with hexane / diethyl ether / acetic acid (70:30:1, by vol). The detection of the spot by TLC was done by spraying the plate with aqueous $\mathrm{H}_{2} \mathrm{SO}_{4}$ and heating it on a hot plate. The FAME fractions were collected and the solvent was removed under vacuum. The isolated FAMEs were dissolved in ethanol and stored at $-30^{\circ} \mathrm{C}$. The yields were obtained directly by dividing the resulting weight of fatty acid methyl esters on the weight of the original oil (Suzuki, et al., 2004).

\section{Analysis of fatty acid composition of me- thyl esters}

Fatty acid composition of the methyl esters were determined by GC. The analysis was performed on a Shimadzu GC-14B chromatograph (Shimadzu Seisakusho, Kyoto, Japan) equipped with an FID and a capillary column (Omegawax $320,30 \mathrm{~m} \times 0.32 \mathrm{~mm}$ i.d.; Supelco, Bellefonte, PA) at a column temperature of $200^{\circ} \mathrm{C}$. The injector and detector temperatures were held at 250 and $260^{\circ} \mathrm{C}$, respectively. Helium was used as carrier gas, with a flow rate of $20 \mathrm{ml} / \mathrm{min}$. Component peaks were identified by comparison with standard FAMEs (Suzuki, et al., 2004).

\section{Isolation of methyl $\alpha$-eleostearate (MeES)}

Methyl $\alpha$-eleostearate (MeES, $\mathrm{C}_{19} \mathrm{H}_{32} \mathrm{O}_{2}=$ 292.5) was prepared from tung oil and isolated using preparative HPLC. The isolated MeES was weighed in ethanol to make the known amount solution of MeES and stored at $-25^{\circ} \mathrm{C}$ (Suzuki, et al., 2004).

\section{Autoxidation of fatty acid methyl esters (FAMEs).}

Each FAME (MeL, MeLn, MeA, MEP and Me $\alpha$-ES) diluted solution $(100 \mu \mathrm{L}=0.50 \mathrm{mg})$ was placed into a 10-ml screw-capped test tube. Then, the diluted MeS solution $(100 \mu \mathrm{L}=0.25 \mathrm{mg})$ was 
added into the test tube. The solvent in each test tube was removed by a centrifuged-evaporator and then by staying under vacuum-chamber for 30 min. Each test tube was incubated in a dark room $40{ }^{\circ} \mathrm{C}$ for $0,8,16$ and $24 \mathrm{hr}$. After incubation, 0.5 $\mathrm{ml}$ of BHT solution ( $1 \mathrm{mM}$ in hexane) was added to terminate the oxidative reaction. The remaining FAME content was determined using liquid chromatography (Suzuki, et al., 2004).

\section{Autoxidation of methyl linoleate in present of $\alpha$-MeES:}

The first experimentation (hydroperoxide) MeL contained $0.1,0.2,1.0$, and $5 \% \alpha$-MeES. Each $0.5 \mathrm{~g}$ of sample oil (MeL without or with MeES) is placed into a glass vial. Each test tube was incubated in the dark at $40{ }^{\circ} \mathrm{C}$ for 8 days. Periodically, $25 \mu \mathrm{L}$ of each oil was collected and dise solved in $1.0 \mathrm{ml}$ of ethanol. This sample solution was stored at $-25^{\circ} \mathrm{C}$ until analysis. The second experimentation (epoxide), MeL and methyl myrisate (Mem) containing $5 \%$ of $\alpha$-MeES were incubated at the conditions same of the first experimentation.

\section{Measurement of peroxide value}

The bulk oil sample $(25 \mu \mathrm{L})$ was dissolved in acetonitril $(1.0 \mathrm{ml})$. This sample solution $(100 \mu \mathrm{L})$ or ethanl (100 $\mu \mathrm{L}$, as a blank) was placed into a test tube, then $25 \mu \mathrm{L}$ of $0.1 \mathrm{M} \mathrm{Na}_{2}$ EDTA in water and $1.0 \mathrm{ml}$ of acetic acid/chloroform $(3: 2, \mathrm{v} / \mathrm{v})$ were added. Finally, each $0.1 \mathrm{ml}$ of saturated KI solution (this solution was prepared just before the experiment) was quickly added in the sample solution. The tube was left at $30 \mathrm{~min}$ in the dark. After the reaction, $4.0 \mathrm{ml}$ of water were added in each tube, mixed by vortex mixer, and centrifuged at $2000 \mathrm{rpm}$ for $5 \mathrm{~min}$. The resulting upper yellow phase $(1.0 \mathrm{ml})$ was withdrawn to another test tube. Water $(4.0 \mathrm{ml})$ was added to this tube and mixed. The produced $\mathrm{I}_{2}$ was measured by the absorbance at $350 \mathrm{~nm}$. The blank test (acetonitril was used instead of the sample solution) before and after measured samples (Wills, 1971).

\section{Measurement the residual amounts of $\alpha$-MeES}

Fatty acid methyl esters in the remaining substrate were determined by GLC using a CP-Sil 88 fused-silica capillary column $(100 \mathrm{~m} \times 0.25 \mathrm{~mm}$ i.d. $\times 0.2 \mu \mathrm{m}$ film thickness, Chrompack, Middelburg, Netherlands) on a Perkin-Elmer chromatograph (Model Clarus, Beaconsfield, UK) equipped with a flame ionization detector. The column was held at $100{ }^{\circ} \mathrm{C}$ for $1 \mathrm{~min}$ after injection, temperatureprogrammed at $7^{\circ} \mathrm{C} / \mathrm{min}$ to $170 \mathrm{C}$, held there for $55 \mathrm{~min}$, then temperature programmed at $10^{\circ} \mathrm{C} / \mathrm{min}$ to $230{ }^{\circ} \mathrm{C}$ and held there for $23 \mathrm{~min}$. Helium was the carrier gas with a column inertsil ODS $(4.6 \mathrm{x}$ $150 \mathrm{~mm}$ ), detection: UV at $273 \mathrm{~nm}$ (absorbance of conjugated triene structure of MeES) and a splitless injection system. Injection volume was $1.0 \mu \mathrm{L}$ $(50 \mathrm{mg} / \mathrm{ml})$. The areas of peaks were calculated using known amounts of MeES as internal standard (Luna et al., 2007).

\section{Statistical analysis}

The data were expressed as mean $\pm \mathrm{SD}$. A oneway ANOVA was also used for statistical analysis between groups. The F ratio of one-way ANOVA is significant when the $\mathrm{P}$ value $\leq 0.05$. Turkey's multiple range method (Scheffe, 1961) was used for comparison. The statistical program was Minitab release 13.31 (Minitab, State College, PA).

\section{RESULTS AND DICUSSION}

\section{The yields of conjugated and non- conju- gated fatty acids of tung oil}

The yields of $\alpha$-elestearic, linoleic, linolenic, arachidonic and ecosapentaenoic acids were 0.521 , $0.848,0.705,0.301$ and $5.18 \mathrm{~g} / 100 \mathrm{~g}$, respectively as shown in Table (1).

\section{Fatty acid composition of tung oil}

The fatty acid composition of tung oil is presented in Table (2). It was observed that the saturated fatty acids present in the oil are palmitic acid $(1.92 \%)$, stearic acid (1.96\%). While, the unsaturated fatty acids present in the oil are oleic acid $(4.75 \%)$, linoleic acid $(6.94 \%), \alpha$-elestearic acid $(79.45 \%)$ and $\beta$-eleostearic acid (4.97\%). The content of unsaturated fatty acids in tung oil amounting to $96.11 \%$ of the total fatty acids. These results are almost compatible with Koji \& Teruyoshi (2005).

Table 1: The yields (g/100 g) of conjugated and non- conjugated fatty acids

\begin{tabular}{|c|c|c|c|c|c|}
\hline Fatty acids & $\alpha$-eleostearic acid & Linoleic acid & Linolenic acid & Arachidonic acid & $\begin{array}{c}\text { Ecosapentaenoic } \\
\text { acid }\end{array}$ \\
\hline Yields (g/100 g) & 0.521 & 0.848 & 0.705 & 0.301 & 5.18 \\
\hline
\end{tabular}


Table (2): Relative percentage of fatty acid composition of tung oil

\begin{tabular}{lcccccc}
\hline & \multicolumn{4}{c}{ Fatty acids } \\
\cline { 2 - 7 } & Palmitic acid & Stearic acid & Oleic acid & Linoleic acid & $\begin{array}{c}\boldsymbol{\alpha} \text {-eleostearic } \\
\text { acid }^{*}\end{array}$ & $\begin{array}{c}\boldsymbol{\beta} \text {-eleostearic } \\
\text { acid }^{*}\end{array}$ \\
\hline Relative \% & 1.92 & 1.96 & 4.75 & 6.94 & 79.45 & 4.97 \\
\hline
\end{tabular}

*: $\alpha$-eleostearic acid and $\beta$ - eleostearic acid are conjugated linolenic acids.

The remaining content of conjugated and non-conjugated methyl esters:

Measurement of the remaining substrate may be necessary when comparing the oxidation of lipids that produce different oxidation products (Luna, et al., 2007). The lipid oxidation products are responsible for the deterioration of lipid-containing foods. Therefore, clarifying the difference in the oxidation products between non-conjugated and conjugated poly unsaturated fatty acids is also important. The oxidative stability and oxidation products of each ester could be characterized by the oxidation of each conjugated or non-conjugated fatty acids. Fig. (1) showed that, methyl $\alpha$ - eleostearate $(\alpha-\mathrm{MeES})$, methyl linoleate (Mel), methyl linolenate (Meln), methyl arachidonate (MeA) and methyl eicosapentaenate (MeE), were oxidized in the dark at $40^{\circ} \mathrm{C}$. Also, it is clear that the time course of the remaining substrates during the oxidation period was 24 hr. It was observed that the contents of remaining $\alpha$-MeES, Mel, Meln, MeA and MeE after $24 \mathrm{~h}$ were $0,72.7,53,13$ and $8.2 \%$, respectively (Fig. $1)$. While, the contents of remaining $\alpha$-MeES, Mel, Meln, MeA and MeE after $16 \mathrm{hr}$ were 10.7, 81,
74.1, 65.6 and 28.2\%, respectively. Comparison between conjugated ( $\alpha$-MeES) and non-conjugated methyl esters (Mel and Meln) with the same number of double bonds showed that the conjugated fatty acids declined more rapidly, and fatty acids with more double bonds (MeA and MeE) also degraded faster. These results agreed with those reported by Jiang \& Kamal-Eldin (1998) and Luna et al., (2007) who mentioned that conjugated linoleic acid absorbs more oxygen per mole of oxidized substrate than linoleic acid and produces mainly polymeric products.

Ha et al., (1990) mentioned that CLA was more oxidatively stable than LA at room temperature. On the contrary, Zhang \& Chen, (1997) reported that CLA was oxidized more rapidly than LA.

\section{Effect of methyl $\alpha$-eleostearate on the auo} toxidation of methyl linoleate:

The data in Fig. (2) show the effect of methyl $\alpha$-eleostearate on the autoxidation of methyl linoleate by using replacement rates $(0.1,0.2,1$ and $5 \%$ of $\alpha$-ES). It was cleared that, the peroxide content increased with increasing storage time (1 to 8 days). Also, the peroxide content increased by using the high percentage of $\alpha$-eleostearate (5\%). In

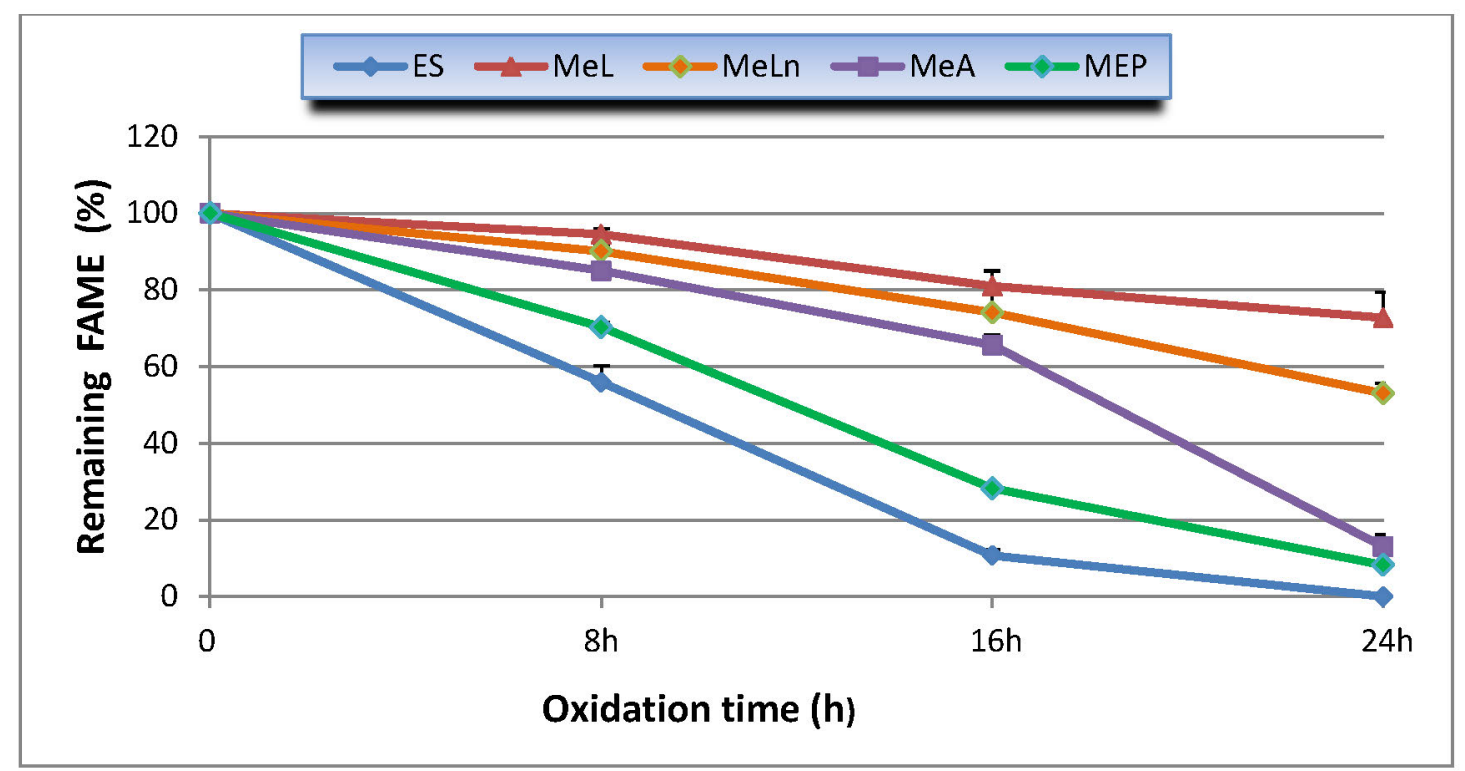

Fig. 1: Time course of the remaining methyl $\alpha$ - eleostearate ( $\alpha$-ES), methyl linoleate (MeL), methyl litl nolenate (MeLn), methyl arachidonate (MeA) and methyl eicosapentaenate (MeEP), oxidized at $40^{\circ} \mathrm{C}$ 


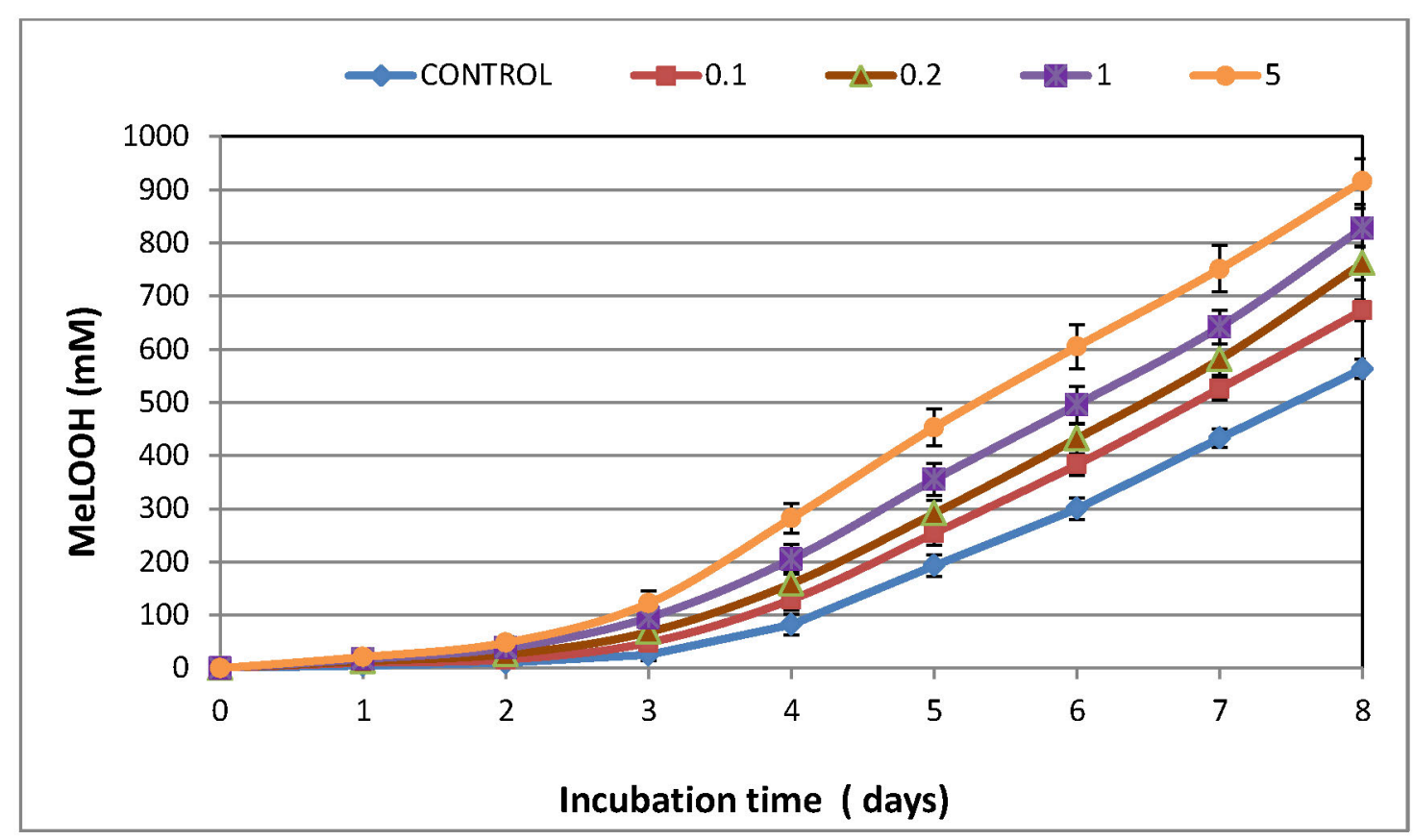

Fig. 2: Effect of methyl $\alpha$-eleostearate on the autoxidation of methyl linoleate, changes in peroxide value by HPLC during the autoxidation in the dark at $40{ }^{\circ} \mathrm{C}$

addition, the peroxide content at $0.1,0.2,1$ and $5 \%$ of $\alpha$-ES were $673,762,828$ and $916 \mathrm{mM}$ at 8 days and $40^{\circ} \mathrm{C}$, respectively. Meanwhile, the peroxide content of methyl linoleate without $\alpha$-ES (control) were $563 \mathrm{mM}$ at 8 days. The oxidative rate of Mel increased with increasing concentrations of $\alpha-$ MeES. These results are in agreement with the data published by Kazuo \& Tom (1986) who reported that during autoxidation, increasing of unsaturated fatty acid increased hydroperoxides resulting from oxidation process.

The remaining methyl $\alpha$-eleostearate during the autoxidation of methyl linoleate

The pro-oxidative effect of $\alpha$-MeES on the au toxidation of Mel was confirmed by the determination of the residual contents. The results presented in Fig. (3) indicated the changes in the amount of the residual of $\alpha$-MeES during the autoxidation in

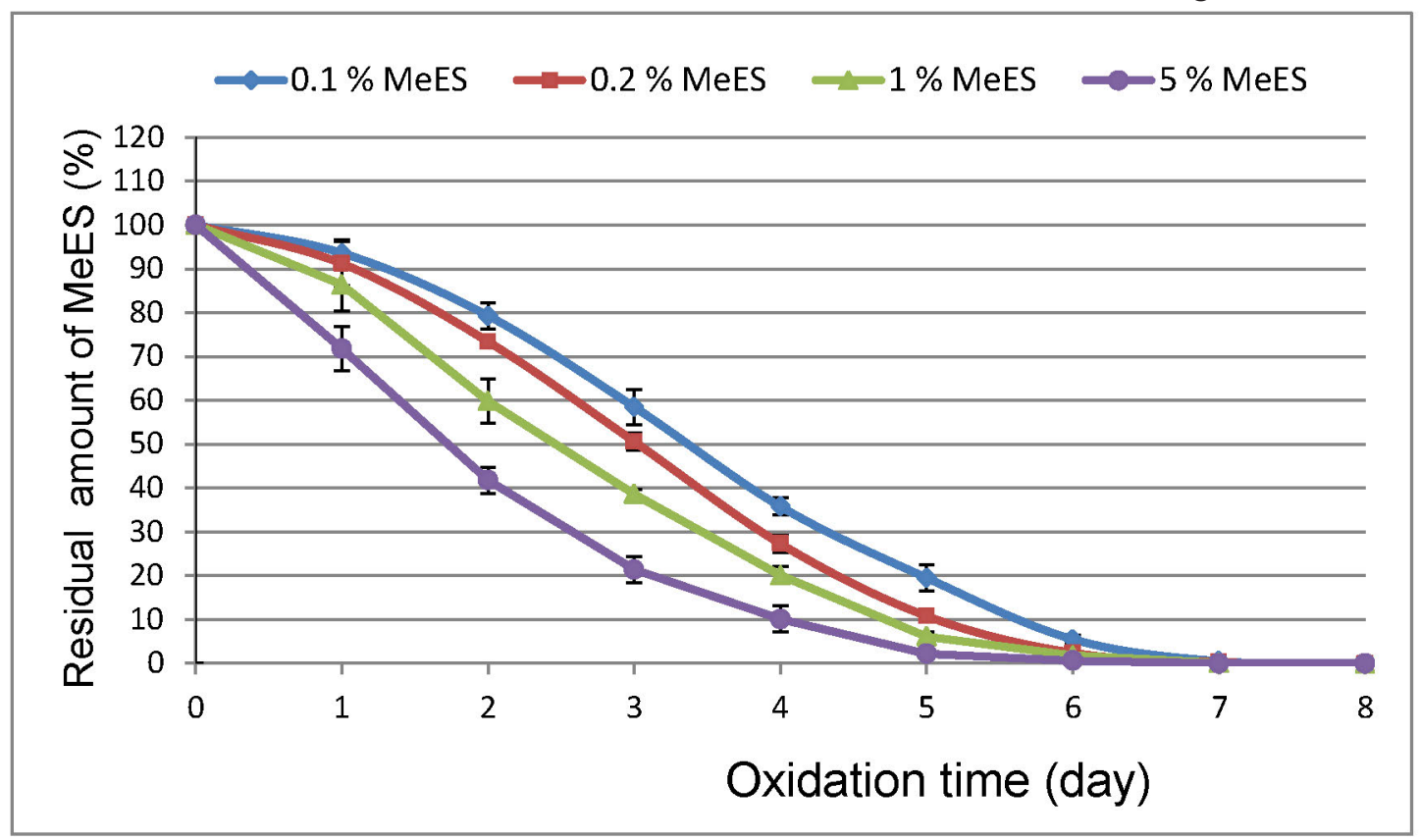

Fig. 3: Effect of methyl $\alpha$-eleostearate on the autoxidation of methyl linoleate, changes in the amount of the residual of $\alpha$-MeES during the autoxidation in the dark at $40^{\circ} \mathrm{C}$ 
the dark at $40{ }^{\circ} \mathrm{C}$. It was observed that the residual of $\alpha$-MeES (\%) decreased with elongation of the storage time. The residual of $\alpha$-MeES (\%) for 0.1 , $0.2,1$ and $5 \%$ were $5.5,2.4,1.8$ and $0.6 \%$ at 6 days, respectively. Meanwhile, it reached to zero $\%$ at 8 days at all percentage of $\alpha$-MeES.

\section{The remaining methyl $\alpha$-eleostearate in MeM and Mel:}

Secondary oxidation products consist of aldehydes, ketones, alcohols, hydrocarbons, volatile organic acids, and epoxy compounds, among others. The results in Fig. (4) indicated that the formation of MeES epoxides resulting from autoxidation of methyl linolate (Mel) contained $5 \% \mathrm{MeES}$ as compared with that of methyl myrstate (MeM) that contained $5 \% \mathrm{MeES}$. The remaining content of $\alpha-$ MeES in Mel was less than that of the remaining content of $\alpha-\mathrm{MeES}$ in MeM. On the other hand, epoxied content of $\alpha-\mathrm{MeES}$ in Mel was less than that of epoxied content of $\alpha$-MeES in MeM during storage period ( 8 days).

\section{CONCLUSION}

Tung oil hold on the higher percentage of $\alpha$-elestearic acid as CFA and also it is much less stable, not only in comparison with the non-conjugated fatty acid, but also more PUFA includ- ing $\mathrm{LnA}$ and $\mathrm{AA}$, when exposed to air oxidation at $40^{\circ} \mathrm{C}$. Future studies on antioxidants studies of $\alpha$-elestearic acid as CLN and its use in food as unsaturated acid.

\section{ACKNOWLEDGEMENT}

The author acknowledges the assistance of Prof. R. Yamauchi (Department of Applied Life Science, Faculty of Applied Biological Sciences, Gifu University, Japan) for his help for carrying out the experiments in his laboratory.

\section{REFERENCES}

Frankel, E.N. 2005. Lipid oxidation. The Oily Press, Dundee. PP: 454-488.

Ha, Y.L., Grimm, N.K. \& Pariza, M.W. 1987. Anticarcinogens from fried ground beef: heataltered derivatives of linoleic acid. Carcinogenesis, 8:1881-1887.

Ha, Y.L., Storkson, J. \& Pariza, M.W. 1990. Inhibition of benzo- (a)pyrene- induced mouse forestomach neoplasia by conjugated dienoic derivatives of linoleic acid, cancer Research, 50:1097-1101.

Igarashi, M. \& Miyazawa, T. 2000. Do conjugated eicosapentaenoic acid and conjugated doco-

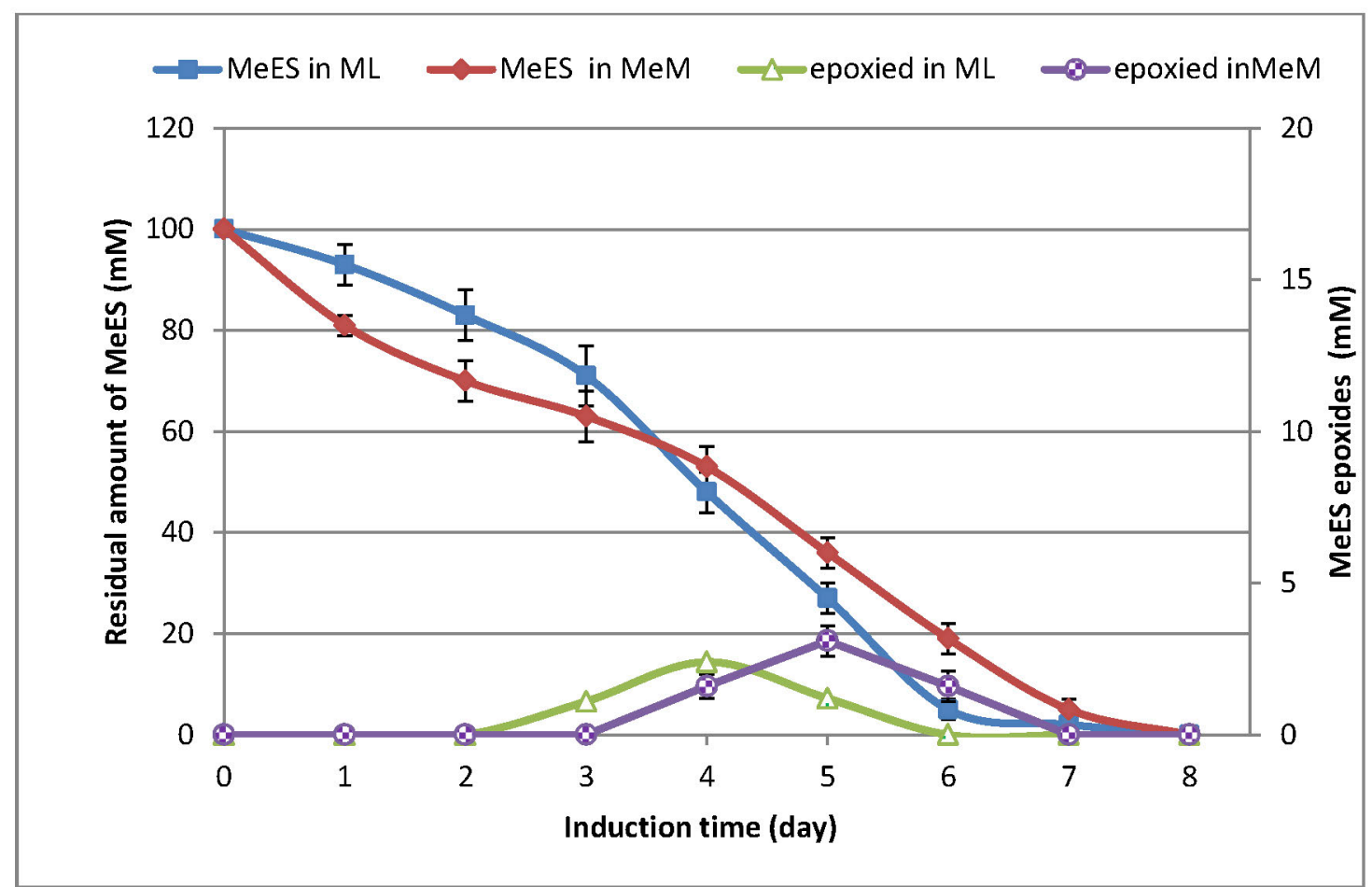

Figure 4: The formation of MeLOOH and MeES epoxides and deletion of MeES at 5\% MeES in MeL autoxidized at $40{ }^{\circ} \mathrm{C}$ 
sahexaenoic acid induce apoptosis via lipid peroxidation in cultured human tumor cells? Biochemical and Biophysical Research Communications, 270:649-656.

Ji, X., Xi, X. L., Kong, L. H., Li, J. F. \& Li, L. 2002. Prospect and technology progress of biodiesel industry. Engineering Science, 4:86-93.

Jiang, J. \& Kamal-Eldin, A. 1998. Comparing methylene blue-photosensitized oxidation methylconjugated linoleate and methyl linoleate. Journal of Agricultural and Food Chemistry, 46:923-927.

Kazuo, M. \& Tom, T. 1986. Study on the oxidative rate and prooxidant Activity of free fatty acids. Journal of the American Oil Chemists' Society, 63: 1380- 1384.

Koji, N. \& Teruyoshi,Y. 2005. Conjugated fatty acids in food and their health benefits. Journal of Bioscience and Bioengineering, 100:152157.

Lin, H., Boylston, T.D., Chang, M.J., Luedecke, L.O. \& Shultz, T.D. 1995. Survey of the conjugated linoleic acid contents of dairy products. Journal of Dairy Science, 78: 2358-2365.

Luna, P., de la Fuente, M. A., Salvador, D. \& Ma'rquez-Ruiz G. 2007. Differences in oxidation kinetics between conjugated and non-conjugated methyl linoleate. Lipids, 42:1085-1092.

Min, E. Z., Tang, Z., Du, Z. X. \& Wu, W. 2005. Perspective of biodiesel industry in china. Engineering Science, 7:1-4.

Park, Y., Albright, K.J., Storkson, J.M., Liu, W., Cook, W.M. \& Pariza, M.W. 1999. Changes in body composition in mice during feeding and withdrawal of conjugated linoleic acid. Lipids, 34:243-248.

Pariza, M.W., Park, Y., Xu, X., Ntambi, J. \& Kang, K. 2003. Speculation on the mechanisms of action of conjugated linoleic acid, in ad- vances in conjugated linoleic acid research. American Oil Chemists' Society Press, Champaign, 2: 251-258.

Pariza, M.W., Yurawecz, M.P., Mossoba, M.M., Kramer, J.K.G. \& Nelson, G.J. 1999. The biological activities of conjugated linoleic acid, in advances in conjugated linoleic acid research. American Oil Chemists' Society Press, Champaign, 1:12-20.

Rainer, L. \& Heiss, C. J. 2004. Conjugated linoleic acid: health implications and effects on body composition. Journal of the American Dietetic Association, 104:963-968.

Scheffe, H. 1961. The Analysis of Variance. John Wiley and Sons, New York. (Sec. 2.2 (pp. 27-28), Sec. 3.6 (pp. 73-74).

Suzuki, R., Abe, M. \& Miyashita, K. 2004. Comparative study of the autoxidation of TAG containing conjugated and non-conjugated C18 PUFA. Journal of American Oil Chemists' Society, 81:563-569.

Takagi, T. \& Itabashi, Y. 1981. Occurrence of mixtures of geometrical isomers of conjugated octadecatrienoic acids in some seed oils: analysis by open tubular gas liquid chromatography and high performance liquid chromatography. Lipids, 16: 546- 551.

Tan, X., Jiang, G., Tan, F., Zhou, W. \& Lu, P. 2011. Research report on industrialization development strategy of Vernicia fordii in China. Nonwood Forest Research, 29: 1-7.

Wills, E. D. 1971. Effects of lipid peroxidation on membrane-bound enzymes of the endoplasmic reticulum. Journal of Biochemistry, 123: 983-991.

Zhang, A. \& Chen, Z.Y. 1997. Oxidative stability of conjugated linoleic acids relative to other polyunsaturated fatty acids. Journal of American Oil Chemists' Society, 74: 1611-1613. 


\title{
التأثير المانع والمسرع للأكسلدة لجامض ألفا إيلوستياركك على الأكسلدة الذاتية لحامض اللينوليك
}

\author{
وليد زكريا بلدوى \\ قسم تكنولوجيا الأغذية - كلية الزراعة - جامعة كفر الشيخ
}

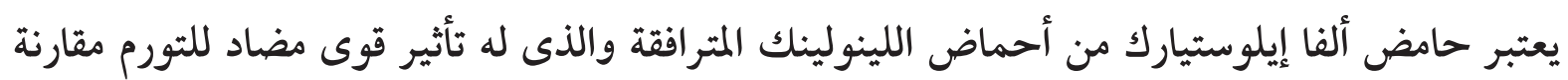

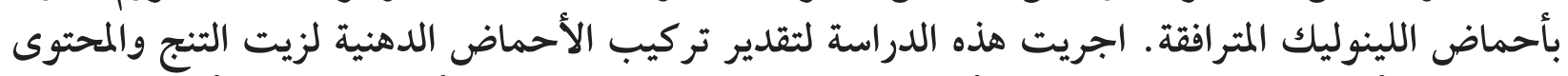

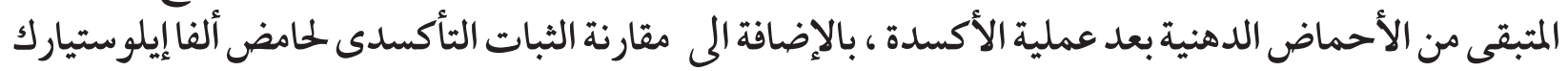

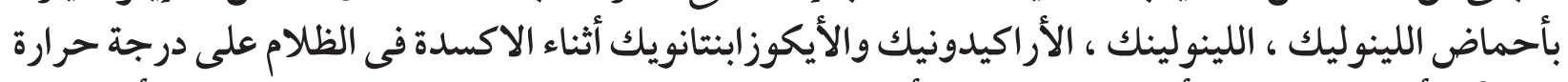

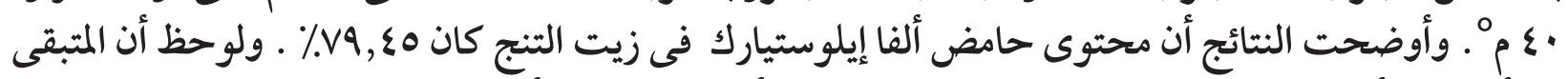

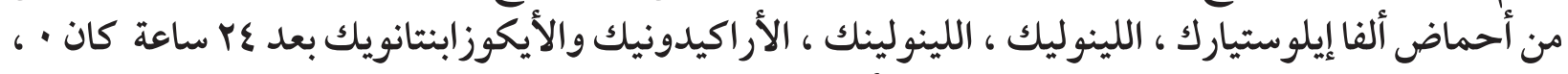

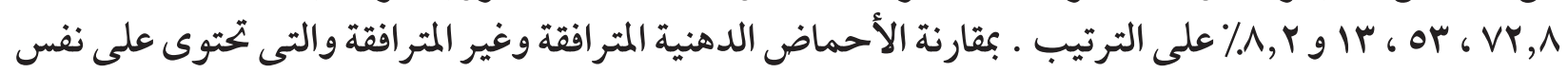

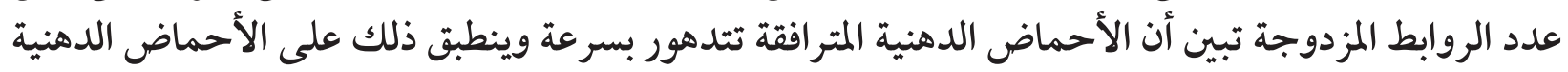

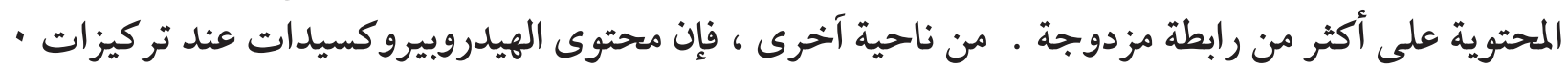

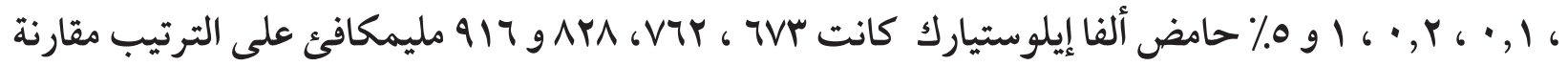

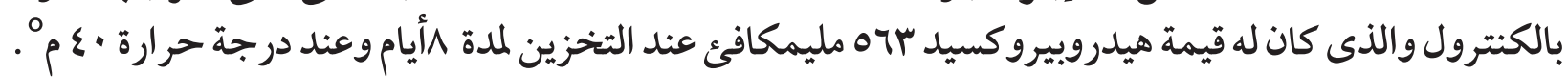

